\title{
'I finally felt like I had power': student agency and voice in an online and classroom-based role-play simulation
}

\author{
Amy Rector-Aranda* and Miriam Raider-Roth \\ Educational Studies, University of Cincinnati, Cincinnati, OH, USA
}

(Received 26 July 2014; final version received 26 February 2015)

\begin{abstract}
This article presents an educational action research study examining how one online, classroom-based role-play simulation offers middle school students the opportunity to strengthen their agency and voice. The Jewish Court of All Time (JCAT) is a web-mediated simulation designed for middle school classrooms where students take on roles of various characters throughout the world, history and literature to address an imaginary court case. JCAT is meant to develop students' skills in writing, critical thinking, perspective-taking, historical empathy and communication, as well as subject literacy in social, historical and cultural contexts. Our research question focuses on how JCAT further encourages and supports the middle school students' agency and voice. We examine how students exercise their agency and voice both in the online environment and in accompanying classroom activities. As an educational action research study, we focus on simulations in which at least one of the authors was a participant, and also pay special attention to how our findings can enhance future simulations. Findings suggest that students constructed knowledge of democratic ideals and were able to exercise their agency and voice specifically, both in the online environment and in accompanying classroom activities.
\end{abstract}

Keywords: democratic education; empowerment; middle school; educational simulations; social studies

\section{Introduction}

In the current era of high-stakes reforms, many concerned stakeholders have reissued a progressive call for more experiential, creative, multicultural and democratic education that develops the whole person, as well as the capacities for critical world citizenship that will be necessary for students to make it in a global society. While legislation and reforms in the United States have been intended to improve student outcomes, they have largely been enacted without fair representation of student perspectives, and the US is not alone in this (Cook-Sather 2006; Levin 2000; Ruddick 2007). Such a massive oversight, or worse yet, intentional exclusion of youth voices in determining their educational trajectories, raises the essential question of how our schools and school policies support and thwart democratic ideals (Gutmann 2012; Westheimer 2008). Internationally, student agency and voice initiatives have shown promise as one way of addressing the apparent inconsistency, by engaging students, improving performance and moving the overall climates of classrooms and schools

*Corresponding author. Email: rectoray@mail.uc.edu

Research in Learning Technology 2015. (C) 2015 A. Rector-Aranda and M. Raider-Roth. Research in Learning Technology is the journal of the Association for Learning Technology (ALT), a UK-based professional and scholarly society and membership organisation. ALT is registered charity number 1063519. http://www.alt.ac.uk/. This is an Open Access article distributed under the terms of the Creative Commons Attribution 4.0 International License (http://creativecommons.org/licenses/by/4.0/), allowing third parties to copy and redistribute the material in any medium or format and to remix, transform, and build upon the material for any purpose, even commercially, provided the original work is properly cited and states its license. 
toward a more egalitarian future (Cook-Sather 2006; Levin 2000; Mitra 2004). The educational action research study discussed in this article examines how one online classroom-based simulation can offer students the opportunity to strengthen their agency and voice. Findings suggest that through this experience, students are taking active roles in how they learn, and discovering unique avenues for making their voices heard.

The subject of the inquiry discussed here is the Jewish Court of All Time (JCAT), a web-mediated simulation designed for middle school-aged students (students in their 7th-9th year) in which they take on roles of various characters throughout the world, history and literature to address an imaginary court case involving ethical decisionmaking. JCAT was created to support a context-specific set of schools (i.e. Jewish Day Schools), and is a sister project to the Place Out of Time simulation (POOT), used for over a decade in secular schools, public, private and charter (Kupperman et al. 2007). Both simulations require students to research their characters, post biographies, speeches and comments as their characters, take on roles as exhibit curators or justices, as well as other various tasks within the simulation and in their classrooms. At the same time, the simulation experience reinforces skills in writing, critical thinking, perspective-taking, historical empathy and communication, as well as subject literacy in social, historical and cultural contexts. The students' teachers, as well as graduate and undergraduate students from two universities and their professors (the project directors), also take part in the simulation as in-character mentors who interact with, support, and play alongside the middle school students.

The simulation scenario for the 2011 iteration of JCAT was a fictitious trial to decide whether reparations were due to the descendants of passengers on the SS. St. Louis, an actual ship of Jewish refugees from Germany to Cuba in 1939 who were refused entry by the U.S. government and sent back to Europe. The 2012 simulation trial focused on the laws being debated and protested in France forbidding the wearing of religious ornamentation in schools, wherein the Jewish and Muslim plaintiffs wished to freely wear their respective religious head adornments. The simulated online trials each lasted 3 months, and all participants took part anonymously while incharacter in the online spaces. In teacher-devised classroom activities, students usually knew each other's identities as they worked together to learn the background of the case topic, and to perfect the authenticity of their character portrayals. Each simulation ended with debriefing questions on the site as well as in-class reflections.

Our research question focused on how JCAT encourages and supports the middle school students' agency and voice. We examined how students exercised their agency and voice both in the online environment and in accompanying classroom activities. As an educational action research study, we focused on simulations in which at least one of the authors was a participant (as mentor or project director), and also paid special attention to how our findings can enhance future simulations.

While recognising that ours is a specific inquiry into a unique case of educational practice, we expect that our findings will illuminate how and why the empowering experience of this online simulation learning environment can be applied to other types of curricula. By highlighting the pedagogical implications of online simulation environments where play is intertwined with rich classroom experiences, we reveal how innovation, creativity and new learning spaces can create agentic learning. We hope to encourage a dialogue about how we, as teachers and researchers, can use these tools to prepare students to think, speak and act as constructive participants in a democratic society. 


\section{Review of literature}

The theoretical framework for this study is rooted in the idea that a principal goal of education is the development of democratic abilities and ideals, particularly agency and voice. As John Dewey (1916) argued 'A democracy ... is primarily a form of associated living, of conjoint communicated experience' (p. 101). In such 'association' and 'communication,' voice and agency are necessary prerequisites. Classrooms, thus, must be experiential spaces where these capacities can be learned.

Beginning with our working definitions, we understand voice as students' ability to express their ideas, opinions, perspectives and needs, as well as to have a say in the methods and direction of their learning (Rector-Aranda 2014). Hadfield and Haw (2007) offer a poignant meaning for student voice, especially as it relates to action research, stating that for some, it is an 'involved act of participation where people engage with the organisations, structures and communities that shape their lives' (p. 488). Voice, therefore, is more than the simple ability to speak one's opinions, but can also be a potent source of personal empowerment for students.

Agency represents an interrelated web made up of student motivation, engagement and voice that creates the essential whole: 'the initiative and capacity to act in a desired direction or toward desired goals' (Toshalis and Nakkula 2012, p. 2). Agency is expressed when students make active choices about how they want to approach their work; accept, resist or take liberty with their assigned tasks; make personal sense of or connections with material; and generally take responsibility for the goals and outcomes of their learning (Reeve and Tseng 2011).

Agency and voice in the classroom are demonstrated in a variety of ways, through the student's intentional and constructive involvement in the learning environment, as intrinsic yet purposeful actions that students utilise to strengthen their own learning, as well as assert their needs and ideas. In our study, we sought to explore how students utilised their voice and agency to meet essential democratic and developmental needs while fulfilling academic responsibilities in their JCAT work.

\section{Agency and voice in role-based online learning environments}

One source of contemporary educational innovation which invites student voice and agentic engagement has been computer-based games and simulations. In role-plays like JCAT specifically, 'students assume the role of a specific stakeholder and negotiate that perspective in the first-person within a fictionalised context' (Schnurr, De Santo, and Green 2014, p. 401). JCAT falls under what Project EnROLE (Encouraging Role Based Online Learning Environments) defines as a learning activity in which role-playing participants negotiate authentic tasks and contexts through substantial human interaction in primarily online environments (Wills et al. 2007). Simulations like these 'allow the development of multiple abilities through their interactivity, immersion and sustained motivation, degree of control, practice, feedback, and authentic experimental learning that would be impossible in a real-life situation' (Sauvé, Renaud, and Kaufman 2010, p. 259). Most authors praise the positive effects of educational gameplay on many levels of learning in both academic and life skills, including the benefits of role-play activities in both face-to-face and online settings (Wills et al. 2007). 


\section{Democratic ideals}

Simulations such as JCAT encourage the skills of a democratic society. Standing in sharp contrast to social studies curricula that mandate memorisation of facts, dates and events, democratic education must encourage students to 'be able to question sources, seek out and manage differing viewpoints, and develop their own interpretations of the information they receive' (Schrier 2007, p. 251). Kupperman et al. (2007) observe that the web-mediated space of JCAT, where everyone must anonymously take on a character role, 'supplants, or at least diminishes, the more familiar student-producing-for-teacher-relationship,' by introducing a space for more 'interaction with mentors and peers ... all of whom are engaged in the rather more egalitarian field of play among fellow-characters' (p. 166). Such simulations purposely offer students opportunities for choice, encourage the ability to think critically about various perspectives, and transform students and adults into cocreators of knowledge. In these ways, students are better enabled to function according to democratic ideals.

\section{Agentic engagement and opportunities for voice}

Akilli (2007) explains the strong relationship between gamers and agentic engagement, in that the 'game generation' wants 'to be treated as "creators and doers" rather than "receptacles to be filled with content"" (p. 3). Simulations as a specific game context, 'offer learners an ideal context for exploration, discovery, communication, practice, and creation of their own understanding of complex phenomenon' (Sauvé, Renaud and Kaufman 2010, p. 259). Throughout the literature, there is a clear link between students' ability to take control of their learning and doing so in simulated educational environments. Another empowering aspect of these games and simulations is that they afford students a measure of control often lacking in traditional education (Schrier 2007). These novel yet productive learning spaces appear to provide just the right combination of structure and liberation.

There remains plenty of room in these games for students to exercise their voice, as well. Kupperman et al. (2007) speculate that 'the protected world of the game allows players to take risks that would not be feasible if they had to be done as the player's own self, with all the attendant social baggage and real-world consequences.' (p. 163). Students in these role-play instances tend to take advantage of the opportunity to anonymously voice their ideas and opinions (Wills et al. 2007). Students likewise appreciate 'the singular experience of being taken seriously, of having one's speech attended to, of being actually heard' (Kupperman et al. 2007, p. 167). The safety of the simulation can bring out voices that might otherwise have remained silent.

\section{Methodology}

This study is one cycle in a larger action research project which seeks to understand the nature of learning among all the stakeholders in the JCAT community. The first cycle focused on the nature of the mentors' learning (Killham et al. 2014); the second focused on the teachers' learning (deNoyelles and Raider-Roth in press); and this study focuses on students' learning. Each cycle of research has shaped the enactment of JCAT as it has unfolded. 
The study employs both inductive and deductive qualitative data methodologies, rooted in an educational/practitioner action research stance. The goal of such a stance is 'the joint construction of local knowledge, the questioning of common assumptions, and thoughtful critique of the usefulness of research generated by others both inside and outside contexts of practice' (Cochran-Smith and Lytle 2009, p. 2). Each of the authors served as a mentor in the simulation, concurrently maintaining the roles of researcher and practitioner. As participants in the simulation, we possessed contextual insight into the experiences had by other participants, and because we were also mentors, we could access all areas of the website, enabling us to see the overall activity in the simulation at a deeper level. It was this positioning that gave us our original perceptions of student agency and voice occurring within the game that, combined with our initial coding, prompted our question for this part of the overall study.

Data collected for this study included three different sources:

- First, we examined student postings from the 2011 and 2012 JCAT 'Green Room' discussion boards (a part of the site inviting participants to post outof-character comments), where students directly answered six questions about their overall experience. A limitation to our reporting of this data source is that these comments are completely anonymous unless the poster mentions who his or her character was, so we cannot differentiate who or how many students actually participated in the data we analysed.

- Second, we examined teacher postings in the 2011 and 2012 teacher professional development site called 'JCAT Talk.' In this online discussion forum, teachers discussed strategies, challenges and questions regarding their teaching in and with JCAT, and their students' learning in the game (deNoyelles and Raider-Roth in press).

- Third, we conducted semi-structured interviews with a purposeful sample of 8 students, 2 teachers and 1 project director, all from the 2012 simulation. Institutional Review Board oversight was sought and received and all data was collected with participant consent $(n=64$ students, 20 teachers, 1 project director).

Our analysis of the data fell into two stages. In our overall work studying the nature of learning in JCAT, we had used grounded theory and open coding of the student Green Room discussions and teacher JCAT Talk discussions. These codes were then 'densified into more enduring and analytically ambitious categories' from which were taken our first insights into student agency and voice (Clark 2007). As these preliminary ideas emerged around student agency and voice, we then formulated pertinent questions for semi-structured interviews with teachers, students and the project director. In the second phase of our analysis, we used a modified deductive framework approach (Pope, Ziebland and Mays 2000). We expanded our thematic framework in order to systematically index the textual data accordingly, organise it into charts around the key themes and categories participants discussed, and finally, interpret the meaning of these themes.

In addition to adhering to the regulations of the university's Institutional Review Board, we have also endeavoured to pay proper consideration to the conventions of action research, utilising the theory of 'covenantal ethics,' which suggests 'a solemn and personally compelling commitment to act in the good of others' (Brydon-Miller 2008). 
To this end, we utilised the 'Structured Ethical Reflection' process to identify and concretise the values we sought to uphold throughout the study (Brydon-Miller, Rector Aranda and Stevens 2015). Through this technique, we identified seven values we wanted to maintain - for example, justice and authenticity - and used these values to interrogate our actions at each phase of the study, from developing partnerships to publication of our results.

\section{Findings}

The above data analysis process yielded two central findings. First, we found a clear theme reflecting students enacting agency and voice through character portrayal. This theme concerns how students were able to express themselves and enact agency, not only in their own voices but also in their characters' voices. A second theme, engagement and empowerment through agency and voice, reflects the range of ways students associated the voice and agency afforded them in game spaces and role-play/ simulation classroom opportunities with their own enjoyment, interest and motivation within the activity. These themes reflect a clear undercurrent of democratic praxis fortifying the experiences of these students, evidenced through the detailed description of each finding below. ${ }^{1}$

\section{Agency and voice through character portrayal}

Student voice and agency were enacted on many levels unique to the JCAT experience, stemming from students' opportunity to express themselves through their character. Within this finding, we identify three central dimensions of student expression: own voice, character voice and exercising agency with character.

\section{Own voice}

The most frequent aspect of voice discussed by both students and teachers was that of the students' own voice. This dimension holds all instances wherein students spoke openly about their ability to express their own ideas and opinions in JCAT through their characters. For example, students used phrases such as 'giving my opinion,' 'share my thoughts,' 'speak my mind,' and 'put my own view out for others to see.' Students even admitted to morphing their characters' opinions on the case to align with their own: 'He had strong opinions as do I so I found a way to align our opinions and then we could have the same one' (Green Room, 12/13/ 2012). 'They've got to sort of make their own sense of things' (1. 66-67), the project director noted, later adding, 'the person who's playing Napoleon doesn't disappear' (1. 91).

Another way students referred to themselves was in reflecting on their challenges in expressing their personal voices, such as apprehensions about their abilities and shyness, as well as how they overcame these challenges. Students also remarked that when they held the same beliefs as their characters, and others in the simulation commented on or supported those beliefs, it was like having their own beliefs validated.

Teachers described students using their own voice when they noticed students expressing their own opinions instead of their characters', when students felt they had 
some say in the unfolding action of the simulation, and when some students overcame their usual shyness or quietness. For example, one teacher shared:

I think for this student it was good to be on the opposite side and to have to deal with that as he often tries to just go along and not express or have an opinion so that he doesn't have to worry that it is at odds with his classmates. I think he might have learned some valuable skills about how you express opposing views and stand up for yourself. Trust me, for this kid, that was invaluable. (Leon Trotsky, 12/9/2011)

As previously noted by Kupperman et al. (2007), the safe space of the simulation appeared to enable students to use their own voices in ways they might not have otherwise.

\section{Character voice}

A student's character in the simulation played a substantial role in his or her experience, with one teacher proclaiming, 'The character makes the difference ... when there's meat to a character it really helps, especially an 11-year-old, to be able to become that person' (Avital Sharansky, 1. 269-271). Students often talked, usually positively, about speaking through their character's voice. In this dimension of agency and voice, students used terms like, 'I could be someone other than myself' and 'to be able to be a different person.' The ability to speak from a perspective not their own, as other students did the same, challenged them to see things from diverse perspectives, and to respect this diversity - a key tenet of democracy. Students generally appeared to take on the roles of their characters whole-heartedly, with several stating that by the end, their in-character responses had become spontaneous and natural.

The project director noted that exercising their character's voice often supported the students' enactment of voice, as they put effort into authentically portraying their character's tone and manner, and in the process brought their own skills of creativity, conjecture and intuition to the table. One teacher found the simulation presented opportunities for students to voice their learning in new ways, stating, 'He has so much trouble writing and he was amazing at orally telling the class all about himself, with some type of Cuban accent going the whole time. Really a great example of how this experience gives kids a chance to show new skills and abilities' (AS, 10/16/2012). Another teacher proclaimed, 'If you knew how mousey and shy she can be, and not terribly confident, you would know how truly impressive it is that she took the initiative and spoke so confidently' (Peter the Great, 10/17/2012). Other teachers noticed that engagement was usually more likely to come from students who were ordinarily engaged in general, but that 'even the students that didn't participate in class ... were able to contribute to the site, and to offer something in a way they don't necessarily do on a daily basis in class' (Groucho Marx, 1. 671-674). The project director concurred that JCAT seems to reach 'some of those students who aren't as good in that mode of writing reports, or whatever it might be, but who bring a lot to the table if they could get the right invitation and the right opportunity' (1. 405-407). Comments such as these suggest that through their characters' voices, many students were able to take risks that they otherwise might not have in their own voices.

Students also conveyed both the difficulties and fascinating elements of combining their own voice with the voice of a character quite different from theirs. 
Some found it was a challenge to explain someone else's ideas, while others saw the challenge in quieting their own ideas. One student revealed, 'It was hard to be someone with not such a big opinion when I had a very big opinion on this case' (Green Room, 12/11/2012). Another student put it this way: 'It's sort of like, basically, you're changing who you are but you're still staying who you are ... you can step into someone else's shoes, but still be an important figure, in something, by still being you' (Nat Holman, 1. 26-31). Juggling these multiple identities was a profound intellectual task for many students.

The project director noted, 'This space between ... character and self, and moving back and forth between them ... enables people to be able to work through things ... by virtue of this detour through these characters' (1. 365-370). He observed that often, figuring out how to balance the two seemed to be 'both exciting and invigorating, but also, in some cases exhausting' (1. 321-322). Teachers also saw evidence of this clash of identities, such as the teacher who said that the 'kids in the class, as themselves, were all in favour of reparations. However, about half of them believed that their characters would have been opposed to reparations' (LT, 12/9/2011). Some teachers found that many such mismatched characteristics actually gave students opportunities to explore multiple perspectives. Through their opportunities within the simulation, students could not only test and explore how and why others have the attitudes and standpoints they do, but also broaden their understandings of themselves and their own positions.

\section{Exercising agency with character}

The third dimension of student agency enacted through character occurred when students knowingly guessed or changed their characters' beliefs and opinions at will, and how teachers noticed students doing so and sought advice on whether to allow it. Like the student in the preceeding section (own voice) who changed his character's beliefs to match his own, other students admitted that they had often guessed at what their character would say.

From the background knowledge, you knew you could like, add your own interpretations, quote unquote, on that character and like become that character without ... disagreeing ... 'cause I have the same beliefs as my character, and, it's nice to like, be sort of able to add on to his beliefs.' (Yehuda HaLevi, 1. 49-55)

Teachers noticed students taking these liberties and were unsure how to respond. 'One challenge that I have had is balancing the "history" elements with the "personality" elements. This is exemplified with the student playing [biblical] Aaron ... who has taken a very modern spin on the character and written the resumé in a very modern, "hip" tone' (GM, 10/15/2012). Given the difficult task of personifying someone they'd never met-and sometimes had little information about-some students made the decision to construct the character's persona as they understood and imagined it, exercising their agency in the process.

\section{Engagement and empowerment through agency and voice}

'When I like wrote a speech, and then I got comments saying like, "I agree," like, "That's a great idea," like compliments on what you write ... that makes you feel like 
I had power' (Aaron, 1. 104-108). Comments such as this alerted us to the ways that students found (or didn't find) forms of engagement and empowerment through enactments of voice and agency in JCAT. Embedded in this overarching theme were the dimensions of intrinsic motivation or rewards, pleasure and controversy, action behind the scenes and missing, silenced or contested use of voice.

\section{Intrinsic motivation or rewards}

An intriguing dimension of this finding regarding engagement and empowerment was that students often showed willingness to do their best work for the intrinsic rewards. As one teacher noted, students spent a lot of unassigned personal time participating in JCAT. 'They were on all night and had their computers out and were making plans 15 minutes before school started this morning' (PtG, 12/4/2012). Students also mentioned this, such as with JCAT discussions and debates they had during recess or in the halls. Additionally, several students indicated how they wanted to make the simulation personally worthwhile, as with the student who said, 'Then I figured ... that it wouldn't make any sense not to try to play my character, so I then tried harder to really be the character' (Hadrian, 1. 24-26). One teacher's comment directly reflects this intrinsic dimension: 'They were discovering for themselves that ... what they put into it would help determine what they got out' (LT, 10/18/2011).

\section{Pleasure and controversy}

One of the reasons JCAT seems to be agentically engaging and empowering for students is that it makes learning a personalised, enjoyable experience. Some students saw JCAT as an escape from traditional coursework. One student proclaimed, 'Yes I loved JCAT so much! It was so much fun and so exciting! It is very hard to make something fun and a learning experience and you guys definitely did that! I wish I could participate again and again!' (Green Room, 12/11/2012). Another student expressed the fun his character Rasputin's eccentricities afforded him, saying, 'I really enjoyed doing the crazy things he could do' (Green Room, 12/12/2012). In general, both students and teachers appeared to see JCAT as an arena for pleasurable and creative learning, which brought on disappointment whenever this goal went unrealised. There were a few comments from students expressing disinterest with this type of learning activity, or who, on the contrary, found it surprisingly enjoyable.

To be honest, I was not looking forward to participating in it at all. It was definitely something that I consider to be out of my comfort zone. However, looking back, I feel as though is was a good activity for me to participate in and that I thoroughly enjoyed it! (Green Room, 12/11/2012)

Teachers did notice that, as with character assignment, engagement was somewhat contingent on the level of controversy in the topic of the trial. For example, the verdict was easier to predict in the 2011 simulation, and one teacher explained, 'there was no controversy for these kids ... it was eye opening, but it wasn't controversial' (AS, 1. 25 \& 32). Another game brought excitement and upheaval when the simulation's host was overthrown by another character, and students had to band together to 'right this wrong' before moving on with the case. 


\section{A. Rector-Aranda and M. Raider-Roth}

This dimension of engagement reveals both the pleasure and controversy that invite students to assert their voices and to assume the risks of taking agentic action in the simulation. Both fun and intrigue invite the students in, to participate and effect the action of the simulation.

\section{Action behind the scenes}

A core dimension of this experience is the work that students and teachers do offline and in their classrooms to support the work within the simulation. They noted rich activity in the classroom that goes unseen to the rest of us, and teachers particularly attended to student agency and voice pedagogically by offering their students opportunities to employ their own resourcefulness and inventiveness in their online tasks and class assignments.

Teachers promoted agency in a variety of subtle ways. One teacher spoke of expecting students to take initiative. Acting through her in-simulation character (her identity unknown to the student), 'I challenged one of my students about what someone "less intelligent" might have to teach me. This provided an opportunity for my student to stand up to a bully and defend others - and they did' (PtG 11/16/2012). Other teachers let students take risks regardless of success potential, gave students opportunities to learn from each other through peer-led activities, and allowed them to choose 'extreme' characters as further illustrations of reinforcing student agency.

Teachers and students also illuminated how the element of student voice played out within the classroom context. One teacher wrote, 'I am listening to their discussions as I type this and they are totally getting what they are doing but I am not sure it is reflected in their posts' (LT, 11/15/2011). Another related that 'for them, a "heated debate" is one in which they are talking across the computer lab and I hear things like "can you believe this?" "Who is Isabella?" etc.' (Ayan Hirsi, 12/10/2011). Students also noticed the classroom dimension of their work. '[A]t times, it was kind of exciting and I kind of liked, like, watching them argue, it was pretty exciting and stuff, but sometimes people ... kind of like took it too far' (Alexander the Great, 1. 236-238). Through comments such as these we can get a glimpse of how students were expressing themselves in the context of classroom activities around JCAT, creating a more complete picture of their experiences of agency and voice in relation to the online simulation.

\section{Missing, silenced or contested use of voice}

As we analysed the comments in the Green Room, the interviews and the site itself, we noticed instances where voice was missing, silenced or contested. Students often expressed complaints about what they saw as the misuse of voice privileges, such as those who saw many public conversations as irrelevant or time-wasting. These instances propelled the question of voice to the forefront of the group discussion. Additionally, a small but troubling number of students wrote of being ignored or feeling unimportant, rendering the potential of their voices missing, as this student, who said, 'I just felt like when I said something about it, no one really cared' (AtG, 1. 156). Another describes, 'I just never got around to it [posting comments] until like 1 month into the project ... then I finally felt like I had power, because before ... it was just like, "I'm just this random person 
on the site"' (YH, 1. 216-217). One teacher commented that students who were not as engaged were also likely to be the students who did not speak up to say so, whether in class, on the site, and/or by not consenting to participate in this study. This prevented us from more accurately understanding what caused their lack of engagement.

\section{Implications and action}

The ideas expressed denote a strong desire for students to actively engage their voices and to exercise greater control over the conditions of their learning. JCAT creates a safe and democratic space where students are encouraged to speak out, partake in community inquiry, and respect different ideas and opinions, all in the safety and structure of a mediated environment. The data illustrates that JCAT creates generous opportunity for students to exert agency and voice in their learning, through their own voices and through the portrayal of their characters, both online and in the classroom. The pleasure and controversy within the simulation invites increased participation in the unfolding of the drama and sparks genuine feelings of purpose and motivation, both online and behind the scenes.

We also found that deliberate attention needs to be paid to gaps in this overall success. As a practitioner action research study, these gaps are important directives for changes in our practice as JCAT mentors and project directors. Students and teachers both expressed the need for more meaningful opportunities to steer the direction of the simulation. In addition, we are aware of those quiet or silent voices from whom we also want to learn, as there remain voices that get lost in the mix. These worries about the tangible power of students' voices reflect the real-world democratic need to make spaces for all voices to be equally heard. We understand these findings as challenges to augment the simulation's capacity to support student voice and agentic engagement in new ways.

To support teachers' agency, the 2014 JCAT simulation invited teachers to join the project directors' team to assist in developing the unfolding drama during the course of the simulation, and a teachers' action research team was formed to support teacher inquiry on their own practice as JCAT teachers. To support student agency and voice, the 2014 JCAT simulation paid very close attention to the 'Green Room' spaces (by creating a role of 'Green Room Manager' which was 'played' by a project director and/or a mentor). In these spaces students often expressed their concerns and frustrations with the simulation, and prompt responses, questions and suggestions were offered.

The findings from this study suggest that JCAT can serve as a model for other online historical and cultural simulations, as well as for general classroom practices and curriculum aimed at supporting student agency and voice. As more innovative experiences are provided in schools, and as educators continue to listen and respond to students' insights, the possibilities for this type of learning are wide-ranging. These learning experiences offer students a chance to increase confidence in their abilities to understand and interact with others, and be empowered to voice their ideas and act with intention and purpose. Such learning opportunities can enable them to fully participate in our democratic way of life, in both the protected spaces of schools and beyond. 


\section{A. Rector-Aranda and M. Raider-Roth}

\section{Acknowledgements}

We would like to thank the Covenant Foundation for their generous sponsorship of this project, and the University of Cincinnati's Center for Studies in Jewish Education and Culture, the University of Michigan's Interactive Communications and Simulations Group and RAVSAK: The Jewish Community Day School Network for supporting this work. We would also like to thank the JCAT teachers and students for sharing their insights with one another and with us, and teaching us deeplyabout their thinking, learning and practice. Many thanks to Jeff Stanzler and the anonymous reviewers for their helpful comments on earlier drafts.

\section{Note}

1. Identifiable participants are distinguished by their characters' full names, and thereafter initials. Dates refer to postings online, and line numbers to interviews. Green Room participants are unidentifiable.

\section{References}

Akilli, G. K. (2007) 'Games and simulations: a new approach in education', in Games and Simulations in Online Learning: Research and Development Frameworks, eds. D. Gibson, C. Aldrich \& M. Prensky, ICI Global, Hershey, PA, pp. 1-20.

Brydon-Miller, M. (2008) 'Covenantal ethics and action research: exploring a common foundation for social research', in The Handbook of Social Research Ethics, eds. D. M. Mertens \& P. E. Ginsberg, Sage, Thousand Oaks, CA, pp. 243-258.

Brydon-Miller, M., Rector Aranda, A. \& Stevens, D. M. (2015) 'Widening the circle: ethical reflection in action research and the practice of structured ethical reflection', in Handbook of Action Research, 3rd edn., ed. H. Bradbury, Sage, Thousand Oaks, CA.

Clark, A. E. (2007) 'Feminisms, grounded theory, and situational analysis', in Handbook of Feminist Research: Theory and Praxis, ed. S. N. Hesse-Biber, Sage, Thousand Oaks, CA, pp. 345-370.

Cochran-Smith, M. \& Lytle, S. L. (2009) Inquiry as Stance: Practitioner Research for the Next Generation, Teachers College Press, New York.

Cook-Sather, A. (2006) 'Sound, presence, and power: "student voice" in educational research and reform', Curriculum Inquiry, vol. 36, no. 4, pp. 359-390.

deNoyelles, A. \& Raider-Roth, M. (in press) 'Being an "agent provocateur:" utilizing online spaces for teacher professional development in virtual simulation games', Technology, Pedagogy and Education.

Dewey, J. (1916) Democracy and Education, Macmillan, New York.

Gutmann, A. (2012) 'Democratic education', in Classic and Contemporary Readings in Philosophy of Education, ed. S. M. Cahn, Oxford University Press, New York, pp. 328-344.

Hadfield, M. \& Haw, K. (2007) "Voice" young people and action research', Educational Action Research, vol. 9, no. 3, pp. 485-502.

Killham, J., et al., (2014) 'Mentoring in an online simulation: shaping pre-service teachers for tomorrow's roles', Teaching and Learning: The Journal of Natural Inquiry and Reflective Practice, vol. 28, no. 2, pp. 62-79.

Kupperman, J., et al., (2007) 'Games, school and the benefits of inefficiency', The International Journal of Learning, vol. 13, no. 9, pp. 161-168.

Levin, B. (2000) 'Putting students at the centre in education reform', Journal of Educational Change, vol. 1, pp. 155-172.

Mitra, D. L. (2004) 'The significance of students: can increasing "student voice" in schools lead to gains in youth development?', Teachers College Record, vol. 106, no. 4, pp. 651-688.

Pope, C., Ziebland, S. \& Mays, N. (2000) 'Qualitative research in health care: analysing qualitative data', BMJ: British Medical Journal, vol. 320, no. 7227, pp. 114-116.

Rector-Aranda, A. (2014) 'Voice', in The SAGE Encyclopedia of Action Research, eds. D. Coghlan \& M. Brydon-Miller, Sage, London, pp. 806-809.

Reeve, J. \& Tseng, C. (2011) 'Agency as a fourth aspect of students' engagement during learning activities', Contemporary Educational Psychology, vol. 36, no. 4, pp. 257-267. 
Ruddick, J. (2007) 'Student voice, student engagement, and school reform', in International Handbook of Student Experience of Elementary and Secondary School, eds. D. Theissen \& A. Cook-Sather, Springer, The Netherlands, pp. 659-680.

Sauvé, L., Renaud, L. \& Kaufman, D. (2010) 'The efficacy of games and simulations for learning', in Educational Gameplay and Simulation Environments: Case Studies and Lessons Learned, eds. L. Sauvé \& D. Kaufman, ICI Global, Hershy, PA, pp. 252-270.

Schnurr, M. A., De Santo, E. M. \& Green, A. D. (2014) 'What do students learn from a roleplay simulation of an international negotiation?', Journal of Geography in Higher Education, vol. 38, no. 3, pp. 401-414.

Schrier, K. (2007) 'Reliving the revolution: designing augmented reality games to teach critical thinking', in Games and Simulations in Online Learning: Research and Development Frameworks, eds. D. Gibson, C. Aldrich \& M. Prensky, ICI Global, Hershey, PA, pp. $250-270$.

Toshalis, E. \& Nakkula, M. J. (2012) 'Motivation, engagement, and student voice', The Students at the Center Series, [online] Available at: http://studentsatthecenter.org/topics/ motivation-engagement-and-student-voice

Westheimer, J. (2008) 'No child left thinking: democracy at-risk in American schools', Democratic Dialogue, vol. 17, pp. 2-9.

Wills, S., et al., (2007) 'Encouraging role based online learning environments', ICT: Providing Choices for Learners and Learning, Proceedings ascilite Singapore 2007, Singapore, pp. 1093-1098. 